This is the penultimate draft of a forthcoming article in Philosophical Papers. Philosophical Papers is available online at: https://www.tandfonline.com/loi/rppa20

\title{
Reasons As Evidence Against Ought-Nots
}

\begin{abstract}
Reasons evidentialism is the view that normative reasons can be analyzed in terms of evidence about oughts (i.e., propositions concerning whether or not S ought to $\Phi$ ). In this paper, I defend a new reason-evidentialist account according to which normative reasons are evidence against propositions of the form S ought not to $\Phi$. The arguments for my view have two strands. First of all, I argue that my view can account for three difficulty cases, cases where (i) a fact is both a reason for $\mathrm{S}$ to $\Phi$ and a reason for $\mathrm{S}$ not to $\Phi$, (ii) a fact is both evidence for the proposition that $\mathrm{S}$ ought to $\Phi$ and evidence for the proposition that $\mathrm{S}$ ought not to $\Phi$, and (iii) the subject is genuinely torn, as far as reasons are concerned, between $\Phi$-ing and not $\Phi$-ing. Second, I argue that my view can account for what a reason against $\mathrm{S} \Phi$-ing is.
\end{abstract}

\section{Keywords}

normative reason, reason, evidence, oughts, reasons for; reasons against

\section{Introduction}

A normative reason for a subject $\mathrm{S}$ to perform an action $\Phi$ is a consideration that counts in favor of $S \Phi$-ing. While some take the concept of reason ${ }^{1}$ to be primitive, denying the

\footnotetext{
${ }^{1}$ Hereafter, unless specified otherwise, 'reason' denotes normative reasons. I will adhere to the widely held view that normative reasons are different from motivating reasons, which are
} 
possibility and plausibility of constructing a substantial analysis of what counts as a reason (cf. Scanlon 1998; Parfit 2011), many disagree. One substantial analysis of reasons characterizes reasons in terms of evidence about propositions concerning whether $\mathrm{S}$ ought to $\Phi$ or not. For lack of a better term, let us call this view 'reasons evidentialism.' In a series of papers, Stephen Kearns and Daniel Star have proposed what has been the most prominent account of reasons evidentialism on the table (Kearns and Star 2008, 2009, 2013, 2015). According to their view, a reason is a piece of evidence for oughts, i.e. evidence for a proposition of the form that $\mathrm{S}$ ought to $\Phi$.

Reasons evidentialism is a view worth serious exploration, but I think Kearns and Star's account is fundamentally misguided. In this paper, I propose a new reasons-evidentialist analysis of reasons, according to which a reason is a piece of evidence against ought-nots, i.e. evidence against a proposition of the form that S ought not to $\Phi$. Kearns and Star's account will be taken as a foil for establishing my account. As will become clear below, critically examining Kearns and Star's account not only reveals the problems of their view but also gives support to the new brand of reasons evidentialism. Because of the limitation of space, the discussion below has left out a couple of important issues such as how plausible reasons evidentialism as a general theory of normative reasons is, how reasons evidentialism fares compared to prominent alternative proposals, etc. But as we will see, we will have enough on our plate.

In what follows, I will first introduce Kearns and Star's reasons-evidentialist analysis of reasons and an alternative analysis that I prefer, specifically highlighting the differences between them (Section 2). I will then consider two kinds of limiting cases, one concerning a

reasons for which we perform a certain action, and from explanatory reasons, which are reasons that explain why we perform the action. 
certain fact being both a reason for S to $\Phi$ and a reason for S not to $\Phi$, while the other concerns a certain fact being both evidence for S ought to $\Phi^{2}$ and evidence for $S$ ought not to $\Phi$ (Sections 3 and 4). Such cases simultaneously give rise to two destructive arguments against Kearns and Star's account as well as two constructive arguments for the new account I propose. Furthermore, I will address what counts as a reason against S $\Phi$-ing (Section 5). I will argue that while Kearns and Star's account cannot account for the reasons-against relation, the new account has no difficulty handling it. I then argue that my account, but not Kearns and Star's, is able to give correct verdicts on cases where, as far as reasons are concerned, one is genuinely torn between $\Phi$-ing and not $\Phi$-ing (Section 6).

\section{Two Accounts of Reasons Evidentialism}

Reasons evidentialism is the view that a reason for $\mathrm{S}$ to $\Phi$ can be analyzed as evidence about propositions regarding whether S ought to $\Phi$ or not. Kearns and Star's $(2008,2009,2013$, 2015) account is the most prominent brand of reasons evidentialism on the market. ${ }^{3}$ According to Kearns and Star (following Kearns and Star, I will use ' $R$ ' to label their view):

(R) Necessarily, a fact $\mathrm{F}$ is a reason for $\mathrm{S}$ to $\Phi$ iff $\mathrm{F}$ is evidence for $S$ ought to $\Phi$. (Kearns and Star 2009, 216)

\footnotetext{
${ }^{2}$ Throughout this paper, propositions will be italicized.

${ }^{3}$ In her (2008) study, Thomson proposes a stronger view, according to which a reason for S to $\Phi$ is evidence for the proposition that S ought to $\Phi$. The following criticisms of Kearns and Star's view apply to Thomson's view as well. I recently learn that Whiting (2018) has defended a similar but different version of reasons evidentialism, according to which reasons are evidence of respect in which it is right to $\Phi$. This is an interesting proposal that I plan to address on another occasion.
} 
In what follows, I follow Kearns and Star (and many others) in assuming that reasons and evidence are facts and that facts are true propositions. Nothing significant hinges upon this assumption. Readers insisting on distinguishing reasons/evidence from facts and/or facts from true propositions may simply regard (R), and reasons evidentialism in general, as contending that a certain reason and a piece of evidence can be characterized by a (true) proposition.

How should we understand the notion of evidence (or evidential support) in play? Kearns and Star accept the orthodox probabilistic account of evidence (or evidential support). On this account, $q$ is evidence for $p$ only if the probability of $p$ will be raised given $q$. That is:

(E1) Necessarily, $q$ is evidence for $p$ only if $\operatorname{Pr}(\mathrm{p} \mid \mathrm{q})>\operatorname{Pr}(\mathrm{p})$.

(R) and (E1) imply that:

(RE) Necessarily, if a fact $\mathrm{F}$ is a reason for $\mathrm{S}$ to $\Phi$, then $\operatorname{Pr}(S$ ought to $\Phi \mid \mathrm{F})>\operatorname{Pr}(S$ ought to $\Phi)$.

Kearns and Star explicitly endorse (E1) and thus (RE) (2009, 231-32). ${ }^{4}$ I also think that (E1) is essentially correct. More important for the present purposes, (E1) helps demonstrate and/or corroborate some of the points I want to make below. ${ }^{5}$ Hence, let us briefly comment on (E1).

First, 'Pr(...)' denotes epistemic probability, which satisfies the standard Kolmogorov axioms ${ }^{6} ;{ }^{\prime} \operatorname{Pr}(\mathrm{p} \mid \mathrm{q})$ ' is defined as $\operatorname{Pr}(\mathrm{p} \& \mathrm{q}) / \operatorname{Pr}(\mathrm{q})$, where $\operatorname{Pr}(\mathrm{q}) \neq 0$. Second, (E1) does not claim

\footnotetext{
${ }^{4}$ However, Kearns and Star also think that rejecting (E1) will have no devastating effect on their view either $(2013,80-81)$.

${ }^{5}$ At any rate, I will assume (E1) in the following discussion, but it should be noted that the main contentions of this paper do not depend on (E1).

${ }^{6}$ The standard Kolmogorov axioms are:
}

(K1) $0 \leq \operatorname{Pr}(\mathrm{p}) \leq 1$

(K2) If $\mathrm{p}$ is a tautology, then $\operatorname{Pr}(\mathrm{p})=1$. 
that $\operatorname{Pr}(\mathrm{p} \mid \mathrm{q})>\operatorname{Pr}(\mathrm{p})^{7}$ is a sufficient condition for $\mathrm{q}$ being evidence for $\mathrm{p}$, and rightfully so — for instance, some philosophers claim that evidence is factive (cf. Williamson 2000; Littlejohn 2011). But since $\operatorname{Pr}(p \mid q)>\operatorname{Pr}(p)$ may hold even if $q$ is false, the right-hand side of (E1) does not imply its left-hand side (also cf. Joyce 2004, 296).

While I take reasons evidentialism to be a promising approach to reasons, I do not think (R) is on the right track. Let ' $F$ is evidence against $p$ ' be defined as ' $F$ is evidence for $\sim p$ '. $I$ propose that the relationship between reasons and evidence regarding whether S ought to $\Phi$ or not is captured by the following (I will use ' $\mathrm{N}$ ' to label this new reason-evidentialist account):

(N) Necessarily, a fact $\mathrm{F}$ is a reason for $\mathrm{S}$ to $\Phi$ iff $\mathrm{F}$ is evidence against $S$ ought not to $\Phi$.

Two comments are called for. Firstly, the main difference between (R) and (N) is that the former takes reasons to be evidence for oughts, while the latter, evidence against ought-nots. Because the relations of evidence-for and evidence-against are mutually definable, (N) can also be formulated in terms of the evidence-for relation-according to $(\mathrm{N}), \mathrm{F}$ is a reason for S to $\Phi$ iff $\mathrm{F}$ is evidence for It is not the case that Sought not to $\Phi$. Likewise, (R) can be formulated in terms of the evidence-against relation-according to (R), $\mathrm{F}$ is a reason for $\mathrm{S}$ to $\Phi$ iff $\mathrm{F}$ is evidence against It is not the case that S ought to $\Phi$.

Secondly, like (R), (N) can be paired with the probabilistic account of evidence, i.e. (E1). To begin with, notice that given the definition of the evidence-against relation, (E1) implies that:

(E2) Necessarily, $q$ is evidence against $p$ only if $\operatorname{Pr}(\sim p \mid q)>\operatorname{Pr}(\sim p)$.

(K3) If $p$ and $q$ are inconsistent, then $\operatorname{Pr}(p \vee q)=\operatorname{Pr}(p)+\operatorname{Pr}(q)$.

${ }^{7}$ For ease of presentation, I will sometimes use ${ }^{‘} \operatorname{Pr}(\mathrm{p} \mid \mathrm{q})>\operatorname{Pr}(\mathrm{p})$ ' as a term and sometimes as a sentence. 
Now, it is a theorem of the probability calculus that $\operatorname{Pr}(p \mid q)>\operatorname{Pr}(p)$ iff $\operatorname{Pr}(\sim p \mid q)<\operatorname{Pr}(\sim p)$. Hence, (E2) is equivalent to:

(E3) Necessarily, q is evidence against $\mathrm{p}$ only if $\operatorname{Pr}(\mathrm{p} \mid \mathrm{q})<\operatorname{Pr}(\mathrm{p})$.

Given (E3), (N) thus implies that:

(NE) Necessarily, if a fact F is a reason for $\mathrm{S}$ to $\Phi$, then $\operatorname{Pr}($ S ought not to $\Phi \mid \mathrm{F})<\operatorname{Pr}(S$ ought not to $\Phi)$.

By way of ending this section, let us address an initial concern. One might worry that $(\mathrm{N})$ and $(\mathrm{R})$ is a distinction without a difference. For one thing, one might think that saying that F is evidence against $S$ ought not to $\Phi$ was just a different way of saying that $\mathrm{F}$ is evidence for S ought to $\Phi$. For another, as $\operatorname{Pr}(\mathrm{p} \mid \mathrm{q})>\operatorname{Pr}(\mathrm{p})$ iff $\operatorname{Pr}(\sim \mathrm{p} \mid \mathrm{q})<\operatorname{Pr}(\sim \mathrm{p})$, one might argue that $\operatorname{Pr}(S$ ought to $\Phi \mid \mathrm{F})>\operatorname{Pr}(S$ ought to $\Phi)$ was equivalent to $\operatorname{Pr}(S$ ought not to $\Phi \mid \mathrm{F})<\operatorname{Pr}(S$ ought not to $\Phi)$. But if so, (RE) and (NE) would be of no difference.

This line of worry is misguided. While $S$ ought to $\Phi$ and $S$ ought not to $\Phi$ are inconsistent, they are not exhaustive. The logical space in effect consists of three mutually exclusive and jointly exhaustive propositions: S ought to $\Phi, S$ ought not to $\Phi$, and It is merely permissible for $S$ to $\Phi($ i.e. Neither $S$ ought to $\Phi$ nor $S$ ought not to $\Phi){ }^{8}$

\footnotetext{
${ }^{8}$ Let us clarify two points. First, the standard treatment of permissibility is that one is permitted to $\Phi$ just in case it is not the case that one ought to $\Phi$. When it is not the case that one ought to $\Phi$ and it is not the case that one ought not to $\Phi$, I will say that it is merely permissible for one to $\Phi$ (or not to $\Phi$ ). Second, mere permissibility is defined negatively, as the denial of the disjunction that either $\mathrm{S}$ ought to $\Phi$ or $\mathrm{S}$ ought not to $\Phi$. I will not attempt to articulate the conditions of mere permissibility.
} 
Now, because 'evidence for' and 'evidence against' are mutually definable, the following principles holds for the right-hand side of $(\mathrm{R})$ and the right-hand side of $(\mathrm{N})$ respectively:

(i) Necessarily, F is evidence for S ought to $\Phi$ iff F is evidence against It is not the case that S ought to $\Phi$.

(ii) Necessarily, F is evidence against S ought not to $\Phi$ iff $\mathrm{F}$ is evidence for It is not the case that $S$ ought not to $\Phi$.

As can be seen in (Table 1), the right-hand side of (i) is different from the right-hand side of (ii). Hence, $(\mathrm{R})$ and $(\mathrm{N})$ are not equivalent. Likewise, $(\mathrm{RE})$ is different from $(\mathrm{NE})$, as can be seen in (Table 2), $\operatorname{Pr}($ S ought to $\Phi \mid \mathrm{F})>\operatorname{Pr}($ S ought to $\Phi)$ is different from $\operatorname{Pr}($ S ought not to $\Phi \mid \mathrm{F})$ $<\operatorname{Pr}(S$ ought not to $\Phi)$.

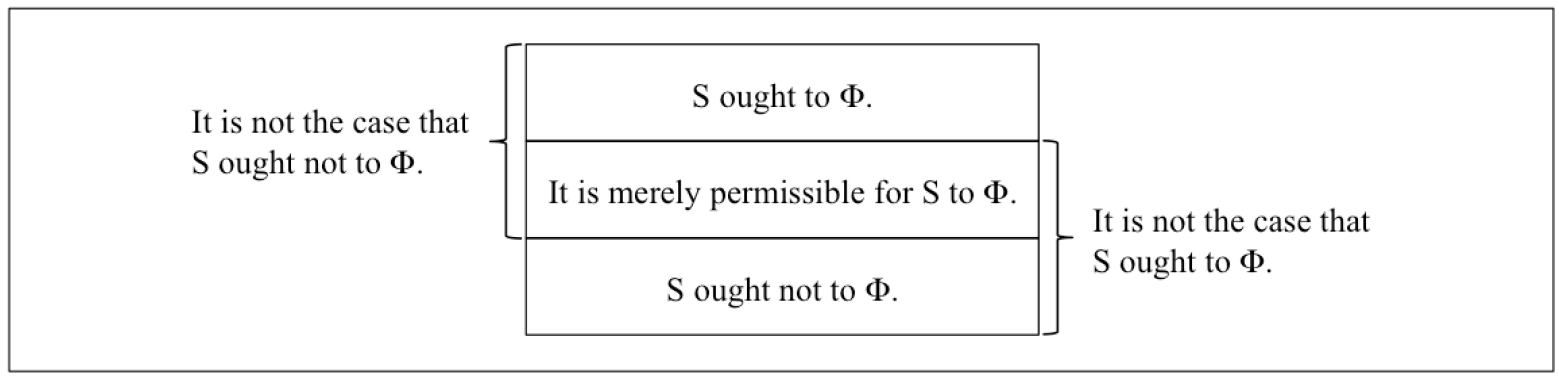

Table 1. The logical space regarding whether S ought to $\Phi$ or not

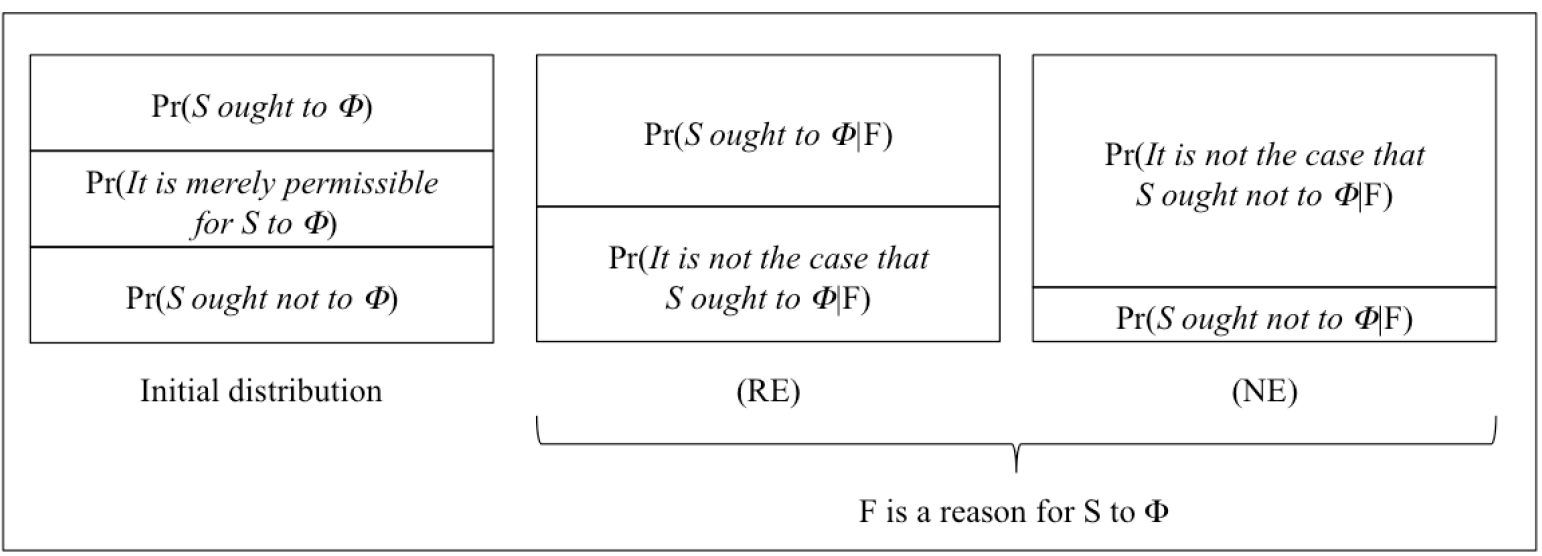

Table 2. The difference between (RE) and (NE) 


\section{Reasons both for $S$ to $\Phi$ and for $S$ not to $\Phi$}

Normally, when $\mathrm{F}$ is a reason for $\mathrm{S}$ to $\Phi, \mathrm{F}$ is not a reason for $\mathrm{S}$ to not $\Phi$. However, it is not impossible for the same fact to be both a reason for $\mathrm{S}$ to $\Phi$ and a reason for $\mathrm{S}$ not to $\Phi$. Consider: Disease. Smith has suffered from a certain disease D. He knows, based on his physician's testimony, that a certain drug $\mathrm{G}$, which contains steroids, is the only effective medicine. Unfortunately, the steroids in $\mathrm{G}$ also have the side effect of causing serious cardiovascular problems. From Smith's perspective, controlling his disease D is as important as avoiding serious cardiovascular problems.

Our intuitive judgments regarding Disease are that:

(1) G contains steroids is both a reason for Smith to take $\mathrm{G}$ and a reason for Smith not to take $\mathrm{G}$.

Any plausible view of reasons will have to leave room for the same fact to be both a reason for acting and a reason for not acting. However, I have also encountered the following worry: 'When F supports both $\Phi$-ing and not $\Phi$-ing to the same degree, wouldn't these two forces cancel out each other? If so, wouldn't it be more plausible to say that $\mathrm{F}$ is neither a reason for $\mathrm{S}$ to $\Phi$ nor a reason for S not to $\Phi$ ?' This reasoning is untenable. In general, just because F's support for $\Phi$-ing is canceled out by an opposite force it does not follow that $\mathrm{F}$ ceases to be a reason for $\Phi$-ing. For instance, suppose that F supports $\Phi$-ing to a certain degree and that $\mathrm{F}^{*}$ supports not $\Phi$-ing to the same degree. That is, F's support for $\Phi$-ing and $F^{*}$ 's support for not $\Phi$-ing cancel out each other. Even so, we will not thus cease to take F to be a reason for $\Phi$-ing. Nor will we cease to take $\mathrm{F}^{*}$ to be a reason for not $\Phi$-ing. By the same token, just because $\mathrm{F}$ is both a reason for $\Phi$-ing and a reason for not $\Phi$-ing it does not follow that $\mathrm{F}$ ceases to be a reason for $\Phi$-ing. Nor does F cease to be a reason for not $\Phi$-ing.

Moreover, the following is also an intuitive verdict regarding Disease: 
(2) G contains steroids, by itself, indicates that it is merely permissible for Smith to take $\mathrm{G}$.

To illustrate, suppose that G contains steroids is the only reason in play in Disease. Under this supposition, it seems clear that Smith is not required to take G, neither is he required not to take G. Instead, it should be entirely up to Smith to decide whether he wants to take G or not, which is exactly the point of (2).

To further bolster (2), notice that (2) is a natural consequence of (1). It is a platitude that, other things being equal, it is not the case that one ought not to act in accordance to one's reasons. Now, according to (1), Smith's reasons support the act of taking G. It is thus not the case that Smith ought not to take G, other things being equal. Likewise, according to (1), Smith's reasons support the act of not taking G. So, it is not the case that Smith ought to take $\mathrm{G}$, other things being equal. In other words, other things being equal, (1) indicates that neither Smith ought to take G nor he ought not to take G, i.e. (2).

With (1) and (2) at hand, it can be demonstrated that (R) cannot account for our intuitive judgments regarding Disease. (R) and (1) imply that:

(3) G contains steroids is both evidence for Smith ought to take $G$ and evidence for Smith ought not to take $G$.

Now, Smith ought to take $G$, Smith ought not to take $G$, and It is merely permissible for Smith to take $G$ are mutually exclusive and jointly exhaustive. Hence, taken most naturally, (3) is tantamount to:

(4) G contains steroids is evidence against It is merely permissible for Smith to take $G$. 
However, (4) is in conflict with (2): according to (4), G contains steroids, by itself, indicates that it is not the case that it is merely permissible for Smith to take G. ${ }^{9}$

That (3) leads to (4) can also be illustrated by the probabilistic account of evidence, too. Specifically, (3) and (E1) imply that:

(3*) $\quad \operatorname{Pr}($ Smith ought to take $G \mid G$ contains steroids $)>\operatorname{Pr}($ Smith ought to take $G)$, and $\operatorname{Pr}($ Smith ought not to take $G \mid G$ contains steroids $)>\operatorname{Pr}($ Smith ought not to take $G)$

From $\left(3^{*}\right)$, we can deduce that:

(4*) $\operatorname{Pr}($ It is merely permissible for Smith to take $G \mid G$ contains steroids $)<\operatorname{Pr}($ It is merely permissible for Smith to take G)

Although (4) is not a logical consequence of $\left(4^{*}\right)$, the former is strongly supported by the latter.

To its merit, (N) can handle cases such as Disease naturally and correctly. First, (N) and (1) imply that:

(5) G contains steroids is both evidence against Smith ought to take $G$ and evidence against Smith ought not to take $G$.

Because $S$ ought to $\Phi, S$ ought not to $\Phi$, and It is merely permissible for $S$ to $\Phi$ are mutually incompatible and jointly exhaustive, it is thus plausible that (5) is tantamount to:

(6) G contains steroids is evidence for It is merely permissible for Smith to take G. Clearly, (N) gives the correct verdict on Disease, as (2) is strongly supported by (6).

\footnotetext{
${ }^{9}$ In fact, Kearns and Star have addressed a case similar to Disease-i.e., a case where the same act is both a reason for $\mathrm{S}$ to $\Phi$ and a reason for $\mathrm{S}$ not to $\Phi$ - and they agree that (R) gives rise to verdicts such as (4) (Kearns and Star 2009, 237-38). However, they fail to see that verdicts such as (4) are in conflict with our intuitions regarding cases such as Disease, i.e. (2).
} 
That $(\mathrm{N})$ leads to (2) can be further demonstrated by the probabilistic account of evidence. That is, given (E3), (5) implies that:

(5*) $\quad \operatorname{Pr}($ Smith ought to take $G \mid G$ contains steroids $)<\operatorname{Pr}($ Smith ought to take $G)$, and $\operatorname{Pr}($ Smith ought not to take $G \mid G$ contains steroids $)<\operatorname{Pr}($ Smith ought not to take $G)$.

$\left(5^{*}\right)$, in turn, implies that:

(6*) $\operatorname{Pr}($ It is merely permissible for Smith to take $G \mid G$ contains steroids $)>\operatorname{Pr}($ It is merely permissible for Smith to take $G$ )

Other things being equal, $\left(6^{*}\right)$ is a very strong piece of evidence for $(2) .{ }^{10}$

Reflecting on cases such as Disease has much to teach us. For one thing, if what has been said so far is correct, we intuitively judge that a certain fact $\mathrm{F}$ is evidence for It is merely permissible for $S$ to $\Phi$ in cases such as Disease. We find (R) implausible precisely because it predicts, incorrectly, that F is both evidence for $S$ ought to $\Phi$ and evidence for $S$ ought not to $\Phi$. Now, by parallel reasoning, one may want to consider cases where a fact $\mathrm{F}$ is both evidence for $S$ ought to $\Phi$ and evidence for $S$ ought not to $\Phi$ - cases that correspond to (R)'s verdicts on cases such as Disease. Will (N) be able to handle such cases? Will such cases favor (R) over (N) instead? This is a suggestive line of thinking that I will turn to in Section 4.

For another thing, cases such as Disease also lead us to consider cases where the subject is genuinely torn, as far as reasons are concerned, between $\Phi$-ing and not $\Phi$-ing. As noted, (R) incorrectly predicts that the reasons in play in cases such as Disease are both evidence for $S$ ought to $\Phi$ and evidence for $S$ ought not to $\Phi$, or equivalently, that the reasons in play are evidence against It is merely permissible for $S$ to $\Phi$. But if so, it seems natural to take the reasons in play to indicate that S both ought to $\Phi$ and ought not to $\Phi$. In other words, according

${ }^{10}$ For a related discussion, see Lee (2020). 
to (R), the subject is genuinely torn, as far as reasons are concerned, between $\Phi$-ing and not $\Phi$ ing in such cases. We find (R) implausible precisely because we intuitively judge that the reasons in play in such cases indicate that it is merely permissible for $\mathrm{S}$ to $\Phi$. However, by parallel reasoning, one may wonder whether things will be very different in cases where we intuitively think that $\mathrm{S}$ is genuinely torn, as far as reasons are concerned, between $\Phi$-ing and not $\Phi$-ing. Will $(\mathrm{N})$ be able to account for such cases? Will such cases favor $(\mathrm{R})$ over $(\mathrm{N})$ instead? This is also a very suggestive line of thinking, but, as will become clear, addressing such cases calls for the concept of 'reasons against $\Phi$-ing', which will be discussed in Section 5. So, I will return to these issues in Section 6, after we have a clear idea of how reasons evidentialists should characterize the reasons-against relation.

\section{Evidence for both $S$ ought to $\Phi$ and $S$ ought not to $\Phi$}

If $\mathrm{F}$ is evidence for $\mathrm{p}$, then $\mathrm{F}$ is typically not evidence for an alternative $\mathrm{p}^{\prime}$ to $\mathrm{p}$. Often but not always. The same F may be both evidence for $S$ ought to $\Phi$ and evidence for Sought not to $\Phi$. Consider:

Greeting. Jenny is sitting in a room, and a stranger is about to enter the room. Jenny knows that there is a fifty-fifty chance that the person entering the room is a normal person, or else this person is a psychopath. Moreover, she knows that if a psychopath enters the room, then there is a fifty-fifty chance that she is a type-1 psychopath, who will be traumatized if not being greeted by Jenny, or else she is a type-2 psychopath, who will be traumatized if being greeted by Jenny. Later, a psychopath enters the room. Two important points regarding Greeting are worth addressing. First, it is intuitive that:

(7) A psychopath enters the room is neither a reason for Jenny to greet the person entering the room nor a reason for Jenny not to greet that person. 
We have to be careful not to misunderstand the point I am making here. For instance, some might reject (7) by reasoning as follows: by stipulation, the psychopath entering the room is either a type-1 psychopath or a type- 2 psychopath. So, the fact that a psychopath enters the room is either a reason for Jenny to greet the person entering the room or a reason for her not to do so. So, the critics concluded, (7) does not hold. However, this objection confuses $A$ psychopath enters the room with A type-1 (type-2) psychopath enters the room. (7) can still hold even if A type-1 (type-2) psychopath enters the room is a reason for Jenny (not) to greet her.

The other point about Greeting worth noting is that:

(8) A psychopath enters the room is both evidence for Jenny ought to greet the person entering the room and evidence for Jenny ought not to greet the person entering the room.

(8), I take it, is in line with the intuitive notion of evidence. ${ }^{11}$

${ }^{11}$ Notice that (8) is different from the following, implausible claim:

(8') A psychopath enters the room is both evidence for and evidence against Jenny ought to greet the person entering the room.

According to the definition of 'evidence against', F is evidence for $S$ ought not to $\Phi$ iff $\mathrm{F}$ is evidence against It is not the case that $S$ ought not to $\Phi$. As a result, (8) is equivalent to the following instead:

(8") A psychopath enters the room is both evidence for Jenny ought to greet the person entering the room and evidence against It is not the case that Jenny ought not to greet the person entering the room.

It is not hard to see that ( $\left.8^{\prime}\right)$ and ( $\left.8^{\prime \prime}\right)$ are not equivalent (also cf. Table 1). 
Not only is (8) intuitively plausible, it can also be manifested by the fact that the following hold in Greeting:

(9) $\operatorname{Pr}($ Jenny ought to greet the person entering the room $\mid$ A psychopath enters the room $)>\operatorname{Pr}($ Jenny ought to greet the person entering the room $)$.

(10) $\operatorname{Pr}(J e n n y$ ought not to greet the person entering the room $\mid$ A psychopath enters the room $)>\operatorname{Pr}($ Jenny ought not to greet the person entering the room $)$.

(9) and (10) strongly support (8), as desired.

It can be demonstrated that (R) cannot account for cases such as Greeting. As stated, Greeting involves (8). (R), together with (8), implies that:

(11) A psychopath enters the room is both a reason for Jenny to greet the person entering the room and a reason for Jenny not to greet that person.

However, (11) denies (7), which, as noted, captures our intuitive judgments regarding Greeting. Thus, (R)'s verdict does not square well with our initial intuitions regarding cases such as Greeting.

It is a further testimony to $(\mathrm{N})$ that it offers a natural account for Greeting. To elaborate, notice that it is an obvious truism that:

(12) Necessarily, if F is evidence for $S$ ought to $\Phi$, then F is not evidence against $S$ ought to $\Phi .^{12}$

From (12), (8) implies that:

\footnotetext{
${ }^{12}$ Notice that F being evidence against $S$ ought to $\Phi$ is different from F being evidence for $S$ ought not to $\Phi$ (also see Footnote 10). Hence, (12) does not imply the following, which is falsified by cases such as Disease:

(12') Necessarily, if F is evidence for Sought to $\Phi$, then F is not evidence for Sought not to $\Phi$.
} 
(13) A psychopath enters the room is neither a piece of evidence against Jenny ought to greet the person entering the room nor a piece of evidence against Jenny ought not to greet the person entering the room.

Given (13), (N) thus implies (7), as desired.

So far, we have seen that $(\mathrm{N})$ outperforms $(\mathrm{R})$ when dealing with cases where $\mathrm{F}$ is both a reason for $\mathrm{S}$ to $\Phi$ and a reason for $\mathrm{S}$ not to $\Phi$ as well as cases where $\mathrm{F}$ is neither a reason for S to $\Phi$ nor a reason for S not to $\Phi$. We will also see, in Section 6, that $(\mathrm{N})$ outperforms $(\mathrm{R})$ in cases where the subject is genuinely torn, as far as reasons are concerned, between $\Phi$-ing and not $\Phi$-ing.

Interestingly, the issue concerning reasons evidentialism still has a final surprise in store. Just like there is a natural distinction between 'evidence for' and 'evidence against', there is also a natural distinction between 'reasons for' and 'reasons against'. Just like any complete account of evidential support should account for both 'evidence for' and 'evidence against', any complete account of reasons for actions should account for both 'reasons for' and 'reasons against'. As I will show in the next section, $(\mathrm{R})$, but not $(\mathrm{N})$, lacks the resources necessary for accounting for the reasons-against relation.

\section{Reasons against $\Phi$-ing}

Both $(\mathrm{R})$ and $(\mathrm{N})$ characterize the reasons-for relation, but because the idea of a reason against $\Phi$-ing is overwhelmingly natural, a complete account of reasons should offer a satisfactory analysis of the reasons-against relation. In what follows, I address how the proponents of (R) and $(\mathrm{N})$ should define the reasons-against relation respectively.

There are only two plausible ways to analyze the reasons-against relation in terms of evidence about oughts/ought-nots: 
(A1) Necessarily, $\mathrm{F}$ is a reason against $\mathrm{S} \Phi$-ing iff $\mathrm{F}$ is evidence against $S$ ought to $\Phi$.

(A2) Necessarily, F is a reason against $\mathrm{S} \Phi$-ing iff $\mathrm{F}$ is evidence for S ought not to $\Phi$. Which one should the reasons evidentialists choose? As far as I know, Kearns and Star did not explicitly address the reasons-against relation.

However, notice two important points. On the one hand, (R) together with (A2) will lead to a conflation between reasons for not $\Phi$-ing and reasons against $\Phi$-ing. Consider, firstly, that the following is a logical consequent of $(\mathrm{R})$ :

(R') Necessarily, F is a reason for S not to $\Phi$ iff $\mathrm{F}$ is evidence for $S$ ought not to $\Phi$. $\left(R^{\prime}\right)$ and (A2) immediately give rise to:

(14) Necessarily, $\mathrm{F}$ is a reason for $\mathrm{S}$ not to $\Phi$ iff $\mathrm{F}$ is a reason against $\mathrm{S} \Phi$-ing.

On the other hand, just like the conjunction of (R) and (A2), the conjunction of (N) and (A1) also leads to a conflation between reasons for not $\Phi$-ing and reasons against $\Phi$-ing, i.e. (14). Consider, firstly, that $(\mathrm{N})$ implies:

(N') Necessarily, F is a reason for $\mathrm{S}$ not to $\Phi$ iff $\mathrm{F}$ is evidence against $S$ ought to $\Phi$. By simple deduction, the conjunction of ( $\left.\mathrm{N}^{\prime}\right)$ and (A1) leads to (14).

To conclude, to the extent that one should avoid conflating reasons for and reasons against, the proponents of $(\mathrm{R})$ and $(\mathrm{N})$ should accept (A1) and (A2), respectively. Below, we will see that this conclusion allows us to see clearly why it is $(\mathrm{N})$, but not $(\mathrm{R})$, that can account for the reasons-against relation. Before we proceed, it may be worth taking a detour and briefly justifying the distinction between reasons for not $\Phi$-ing and reasons against $\Phi$-ing.

While some might want to deny this distinction (cf. Nagel 1979, 47, footnote 1), the distinction has a basis in both the ordinary and distinctively philosophical considerations of reasons. I will elaborate on them respectively. 
Firstly, as Jonathan Dancy has pointed out, we all have 'an independent understanding' of the difference between reasons for and reasons against (Dancy 2015, 182). Indeed, a reason 'for' $\Phi$-ing can be understood as providing support for $\Phi$-ing, whereas a reason 'against' $\Phi$ ing can be understood as counting against $\Phi$-ing. This suggests that a reason for $S$ to $\Phi$ is a consideration in favor of $\mathrm{S} \Phi$-ing, whereas a reason against $\mathrm{S} \Phi$-ing is a consideration prohibiting S from $\Phi$-ing. Clearly, the in-favor-of role and the prohibiting role are not identical. In particular, to favor S not to $\Phi$ is different from prohibiting $S$ from $\Phi$-ing. Just because not $\Phi$-ing is a favorable option, it does not mean that $\Phi$-ing is prohibited.

Admittedly, the difference between reasons for not $\Phi$-ing and reasons against $\Phi$-ing can be subtle, and in many cases, people do not always separate two kinds of negative reasons. But I take it that, when framed appropriately, ordinary people are inclined to drive a wedge between a reason for not $\Phi$-ing and a reason against $\Phi$-ing. Patricia Greenspan gives such an example. Suppose that the fact that I look best in green is a reason for me not to wear a blue jacket. Still, this fact is not a reason against me wearing a blue jacket— 'unless there is some reason why I need to look my best, blue may be perfectly acceptable' (Greenspan 2005, 387). Likewise, the fact that John is wealthy is a reason for me not to donate money to him, but unless donating money to the wealthy will cause harm to somebody, I am not forbidden to donate money to him.

This does not mean that reasons for not $\Phi$-ing and reasons against $\Phi$-ing are mutually independent. While not all reasons for not $\Phi$-ing are reasons against $\Phi$-ing, the reverse - all reasons against $\Phi$-ing are reasons for not $\Phi$-ing-does seem to hold. After all, if S is prohibited from $\Phi$-ing, it is favorable that $S$ does not $\Phi$. For instance, the fact that firing the gun will kill an innocent citizen is a reason against me firing the gun. And it is also a reason for me not to 
do so. Perhaps this also explains why people do not always separate reasons against $\Phi$-ing from reasons for not $\Phi$-ing.

Secondly, the normative forces involved in the reasons-against- $\Phi$-ing relation may be different from (and indeed stronger than) the ones involved in the reasons-for-not- $\Phi$-ing relation. A reason against $S \Phi$-ing involves a compelling force of forbidding $\mathrm{S}$ from $\Phi$-ing that a reason for S not to $\Phi$ may lack (cf. Greenspan 2005; 2007). Arguably, doing what is forbidden is blameworthy, other things begin equal. It follows that, other things being equal, one is blameworthy for performing an action that one's reasons are against performing. For instance, if Firing the gun will kill an innocent citizen is a reason against me firing the gun, then, other things being equal, my act of firing the gun is blameworthy. By contrast, other things being equal, one's performance of an action may be blameless even if the reasons in play support not performing the action. For instance, while John is wealthy is a reason for me not to donate money to him, I am not blameworthy for donating money to him, unless we are to blame anyone who fails to make the best use of their money.

Thirdly, there is also a structural reason against conflating reasons for not $\Phi$-ing with reasons against $\Phi$-ing. Depending on the scope of the negation, the denial of $S$ ought to $\Phi$ has two interpretations. On the narrow-scope-negation interpretation, the denial of $S$ ought to $\Phi$ is S ought not to $\Phi$, while on the wide-scope-negation interpretation, the denial of $S$ ought to $\Phi$ is It is not the case that Sought to $\Phi$. Now, it is widely accepted that reasons play a significant role in determining whether one ought to $\Phi$, or that reasons and oughts/ought-nots are inextricably intertwined with each other. If so, we should expect the structural distinction between the narrow- and wide-scope denials of $S$ ought to $\Phi$ to be somehow reflected in the structure of the reasons concerning $\Phi$-ing. That is, there should be a corresponding distinction between two kinds of negative reasons concerning $\Phi$-ing. 
We have seen that the distinction between reasons for and reasons against is supported by initial intuitions and principled considerations. Admittedly, there is still much to be said about the distinction, ${ }^{13}$ but for the present purposes, a general admission of the essential distinction between reasons for and reasons against is not required. All we need, instead, is to establish that reasons evidentialism has to admit such a distinction. In fact, reasons evidentialism is under specific pressure to admit these two kinds of negative reasons, for the distinction between the narrow- and wide-scope denials of oughts/ought-nots naturally carries over to evidence about oughts/ought-nots. More exactly, corresponding to the distinction between the narrow-scope and wide-scope denials of oughts/ought-nots, there is also a distinction between what we may call the narrow-scope and wide-scope negative evidence about oughts/ought-nots, namely, the distinction between evidence for $S$ ought not to $\Phi$ and evidence for It is not the case that $S$ ought to $\Phi$. Because the crux of reasons evidentialism is to regard reasons for actions as equivalent to evidence about oughts/ought-nots, that there are two kinds of negative evidence about oughts/ought-nots indicates that there should also be two kinds of negative reasons for actions. The distinction between reasons for not $\Phi$-ing and reasons against $\Phi$-ing is an obvious and natural candidate for capturing the distinction between evidence for It is not the case that $S$ ought to $\Phi$ and evidence for $S$ ought not to $\Phi$. Conflating the former distinction will not make the latter distinction disappear-if anything, doing so only implausibly deprives reasons evidentialism of an intuitive source of accounting for these two kinds of negative evidence about oughts/ought-nots.

${ }^{13}$ A number of authors have recently argued against identifying reasons for with reasons against, too (cf. Snedegar 2018; Metz 2018). 
Enough for the detour. Let us get back to how (R) would handle the reasons-against relation. For one thing, as pointed out above, the set of reasons against $\Phi$-ing is a proper subset of the set of reasons for not $\Phi$-ing. (R), however, fails to account for this phenomenon.

To elaborate, notice that:

(15) All evidence for S ought not to $\Phi$ is evidence for It is not the case that $S$ ought to $\Phi$ but not the other way around.

For instance, if $\mathrm{F}$ is evidence for, say, Jones ought not to kill Jenny, then of course, F is ipso facto evidence for It is not the case that Smith ought to kill Jenny. By contrast, just because F is evidence for, say, It is not the case that Smith ought to go to school it does not follow that F is evidence for Smith ought not to go to school-F may simply support It is merely permissible for Smith to go to school. For the present purposes, the important point is that, given (15), (R') and (A1) imply that the set of reasons for not $\Phi$-ing is a proper subset of the set of reasons against $\Phi$-ing, a verdict, as noted before, that runs counter to our ordinary intuitions.

By contrast, $(\mathrm{N})$ is substantiated by its capacity of providing an appropriate explanation of the phenomenon in question. That is, given (15), ( $\left.\mathrm{N}^{\prime}\right)$ and (A2) imply that the set of reasons against $\Phi$-ing is a proper subset of the set of reasons for not $\Phi$-ing, as desired.

For another thing, reflecting on the following case template leads us to see that $(\mathrm{N})$ but not $(\mathrm{R})$ correctly characterizes the ordinary notion of reasons against $\Phi$-ing:

(CT) F is a reason against $\mathrm{S} \Phi$-ing, and $\mathrm{F}$ is the only relevant reason in play. For any case $\mathrm{C}$ satisfying $(\mathrm{CT})$, it seems intuitive that, other things being equal, the subject $\mathrm{S}$ in C ought not to $\Phi$. For instance, suppose that Firing the gun will kill 10 innocent people is a reason against Smith firing the gun and that this fact is the only relevant reason in play. With these suppositions, it does seem intuitive that, other things being equal, Smith ought not to fire the gun. 
Let us examine how (A1) and (A2) will handle cases satisfying (CT) respectively. According to (A1), other things being equal, (16) holds in all the cases satisfying (CT):

(16) F is evidence against $S$ ought to $\Phi$.

The problem, however, is that (16) is compatible with:

(17) $\quad \mathrm{F}$ is evidence for It is merely permissible for $S$ to $\Phi$.

The proof is rather straightforward: one way for F to be evidence against $S$ ought to $\Phi$ is for $\mathrm{F}$ to be evidence for It is merely permissible for $S$ to $\Phi$. As a result, accepting (16) is compatible with accepting (17).

The compatibility between (16) and (17) can also be illustrated by the probabilistic account of evidence; more exactly, by the fact that $\left(16^{*}\right)$ and $\left(17^{*}\right)$ are compatible:

$\left(16^{*}\right) \quad \operatorname{Pr}(S$ ought to $\Phi \mid \mathrm{F})<\operatorname{Pr}(S$ ought to $\Phi)$

$\left(17^{*}\right) \operatorname{Pr}($ It is merely permissible for $S$ to $\Phi \mid \mathrm{F})>\operatorname{Pr}($ It is merely permissible for $S$ to $\Phi)$

$\left(16^{*}\right)$ and $\left(17^{*}\right)$ strongly support (16) and (17) respectively. So, the compatibility between $\left(16^{*}\right)$ and $\left(17^{*}\right)$ show that (16) and (17) are also compatible.

We can now see that (A1) fails to give the correct verdicts regarding cases satisfying (CT): given that the proponents of (A1) have to accept (16) and that (16) is compatible with (17), they must thereby admit the implausible claim that it is possible for (17) to obtain in cases satisfying (CT), or that, other things being equal, it may be merely permissible for $\mathrm{S}$ to $\Phi$ in cases satisfying (CT). However, intuitively, (17) cannot hold in cases satisfying (CT). Put another way, it is a truism that mere permissibility implies permissibility, namely, if it is merely permissible for $\mathrm{S}$ to $\Phi$, then it is permissible for $\mathrm{S}$ to $\Phi$. Hence, the proponents of (A1) must commit to an unpalatable contention that, other things being equal, it may be permissible for $\mathrm{S}$ to $\Phi$ in cases satisfying (CT). Now, because the proponents of (R) must accept (A1), it follows that $(\mathrm{R})$ cannot account for such cases as well. 
(A2), by contrast, gives a natural and correct account of cases satisfying (CT). The idea is that (A2) implies that, other things being equal, (18) holds in all cases satisfying (CT):

(18) F is evidence for Sought not to $\Phi$.

Obviously, (18) indicates that, other things being equal, S ought not to $\Phi$ in cases satisfying $(\mathrm{CT})$, as desired. Becaue the proponents of $(\mathrm{N})$ have to accept (A2), it is clear that they are in a position to offer a satisfactory account of such cases.

\section{Being Genuinely Torn between $\Phi$-ing and not $\Phi$-ing}

At the end of Section 3, we mentioned cases where the subject is genuinely torn between $\Phi$ ing and not $\Phi$-ing. Admittedly, there are different ways for a subject to be so torn, but for the present purposes, I will focus on cases where the subject's tension has its roots in the reasons in play, namely, cases where the reasons in play indicate that the subject both ought to $\Phi$ and ought not to $\Phi$. Are such cases possible? I think they are. Some cases of moral conflict, for instance, appear to be a case in point ${ }^{14}$ - on one standard formulation, one faces a moral conflict when it is the case that one both ought to $\Phi$ and ought not to $\Phi$ (cf. Williams 1973, 171). ${ }^{15}$ I will argue in this section that $(\mathrm{N})$ can account for such cases naturally, while the same cannot be said of $(\mathrm{R})$.

In order to see how reasons evidentialism will deal with cases where one is genuinely torn, as far as reasons are concerned, between $\Phi$-ing and not $\Phi$-ing, we need to know what

\footnotetext{
${ }^{14}$ This certainly does not mean that such cases only arise from moral conflict. Nor does it mean that all cases of moral conflict are generated by the tension between reasons.

${ }^{15}$ Moral conflict is a significant topic on its own. While I am sympathetic to the idea that all cases of moral conflict consist in the subject being torn, as far as reasons are concerned, between $\Phi$-ing and not $\Phi$-ing, I will not address the issue here.
} 
kind of reasons regarding S $\Phi$-ing (or not $\Phi$-ing) is in play here. Two prominent candidates suggest themselves: either (a) the reasons in play in such cases consist of both reasons for $\mathrm{S}$ to $\Phi$ and reasons for S to not $\Phi$, or (b) they consist of both reasons against $\mathrm{S} \Phi$-ing and reasons against S not $\Phi$-ing. Now, the aforementioned discussion shows that (a) is unacceptable. As shown by Disease, cases in which (a) holds are such that the reasons in play rather indicate that it is merely permissible for the subject to $\Phi$. Hence, it is not the case that the subject both ought to $\Phi$ and ought not to $\Phi$ in cases in which (a) holds.

In other words, a subject is genuinely torn, as far as reasons are concerned, between $\Phi$ ing and not $\Phi$-ing only if she is in cases where (b) holds. If so, it can be shown that $(\mathrm{N})$ gives the correct verdicts regarding such cases. First, let us consider how (R) will handle such cases.

Recall that the proponents of (R) have to accept (A1):

(A1) Necessarily, $\mathrm{F}$ is a reason against $\mathrm{S} \Phi$-ing iff $\mathrm{F}$ is evidence against $S$ ought to $\Phi$.

Consider a limiting case of (b) such that a certain F is both S's reason against $\Phi$-ing and S's reasons against not $\Phi$-ing. ${ }^{16}$ According to (R), hence, the following holds in this case:

(19) F is both evidence against $S$ ought to $\Phi$ and evidence against $S$ ought not to $\Phi$. Arguably, (19) is tantamount to:

(20) F is evidence for It is merely permissible for $S$ to $\Phi$. That (19) is tantamount to (20) can be illustrated by the probabilistic account of evidence, too. More precisely, given (E3), the following can be derived from (19):

(19*) $\operatorname{Pr}(S$ ought to $\Phi \mid \mathrm{F})<\operatorname{Pr}(S$ ought to $\Phi)$, and $\operatorname{Pr}(S$ ought not to $\Phi \mid \mathrm{F})<\operatorname{Pr}(S$ ought not to $\Phi)$.

${ }^{16}$ Admittedly, such cases are not typical, but they are surely not impossible. 
$\left(19^{*}\right)$, in turns, implies that:

$\left(20^{*}\right) \operatorname{Pr}($ It is merely permissible for $S$ to $\Phi \mid \mathrm{F})>\operatorname{Pr}($ It is merely permissible for $S$ to $\Phi)$

$\left(20^{*}\right)$ gives a very strong support for (20).

(20), however, indicates that, other things being equal, it is merely permissible for $\mathrm{S}$ to $\Phi$ (or not to $\Phi)$. In other words, (20) shows that, other things being equal, $\mathrm{S}$ is not torn between $\Phi$-ing and not $\Phi$-ing. As a result, as (R) predicts that (20) holds in certain cases where $\mathrm{S}$ is genuinely torn, as far as reasons are concerned, between $\Phi$-ing and not $\Phi$-ing, (R) has failed to give a correct verdict regarding such cases.

$(\mathrm{N})$, by contrast, gives the desired verdict. Recall that the proponents of $(\mathrm{N})$ have to $\operatorname{accept}(\mathrm{A} 2)$ :

(A2) Necessarily, F is a reason against S $\Phi$-ing iff $\mathrm{F}$ is evidence for S ought not to $\Phi$. Consider, again, a limiting case of (b) such that a certain F is both S's reasons against $\Phi$-ing and S's reason against not $\Phi$-ing. According to $(\mathrm{N})$, then, the following holds in such a case:

(21) F is both evidence for $S$ ought to $\Phi$ and evidence for $S$ ought not to $\Phi$.

(21) indicates that, other things being equal, S both ought to $\Phi$ and ought not to $\Phi$. That is, (21) gives the desired verdict that $\mathrm{S}$ is genuinely torn, as far as reasons are concerned, between $\Phi$ ing and not $\Phi$-ing in this case.

\section{Conclusion}

Roughly, I have argued that a reason for S to $\Phi$ should be analyzed in terms of evidence against S ought not to $\Phi$, i.e. (N). My view is in stark contrast to Kearns and Star's view, according to which $\mathrm{F}$ is a reason for $\mathrm{S}$ to $\Phi$ iff $\mathrm{F}$ is evidence for $S$ ought to $\Phi$, i.e. (R). The latter serves as a foil for the former: by measuring $(\mathrm{N})$ against (R), I propose two strands of arguments for $(\mathrm{N})$. 
On the one hand, I argue that $(\mathrm{N})$, but not (R), can account for three kinds of limiting cases, namely, cases where the same fact constitutes both a reason for S to $\Phi$ and a reason for $\mathrm{S}$ not to $\Phi$ (such as Disease), cases where the same piece of evidence supports both Sought to $\Phi$ and S ought not to $\Phi$ (such as Greeting), and cases where the subject is genuinely torn, as far as reasons are concerned, between $\Phi$-ing and not $\Phi$-ing. On the other hand, I argue that $(\mathrm{N})$, but not $(\mathrm{R})$, gives rise to a plausible account of the reasons-against relation.

This paper is part of an ongoing, larger project of establishing/defending $(\mathrm{N})$, and as such I have left a number of important questions unanswered here. How plausible is reasons evidentialism as a general theory of normative reasons? How does $(\mathrm{N})$ fare in comparison to prominent alternative proposals? Such questions become more pressing once we recognize that there has been no shortage of objections to reasons evidentialism: while some are specifically targeted at Kearns and Star's brand of reasons evidentialism, others are more sweeping objections targeted at the idea of reasons as evidence about oughts/ought-nots (cf. Brunero 2009; McKeever and Ridge 2012; Finlay 2014; Littlejohn 2016). Several alternative views on reasons have also been powerfully defended (Broome 2004, 2013; Finlay 2014; Nebel 2018; Whiting 2018). However, as one can only do so much in a single paper, these issues will have to be left for another occasion.

\section{References}

Broome, John. 2004. "Reasons." In Reason and Value: Themes from the Moral Philosophy of Joseph Raz, edited by R. Jay Wallace, Philip Pettit, and Samuel Scheffler, 28-55. Oxford: Clarendon Press.

Brunero, John. 2009. "Reasons and Evidence One Ought.” Ethics 119 (3): 538-45. 
Dancy, Jonathan. 2015. “Reasons for Broome.” In Weighing and Reasoning: Themes from the Work of John Broome, edited by Iwao Hirose and Andrew Reisner, 177-88. New York: Oxford University Press.

Finlay, Stephen. 2014. Confusion of Tongues: A Theory of Normative Language. Oxford: Oxford University Press.

Greenspan, Patricia. 2005. “Asymmetrical Practical Reasons.” In Experience and Analysis, edited by Maria E. Reicher and Johann Christian Marek, 384-97. Vienna: ÖBV \& HPT.

Joyce, Jim. 2004. “Williamson on Evidence and Knowledge.” Philosophical Books 45: 296305.

Kearns, Stephen, and Daniel Star. 2008. “Reasons: Explanations or Evidence?” Ethics 119: $31-56$.

—. 2009. "Reasons as Evidence." In Oxford Studies in Metaethics, edited by Russ Shafer-Landau, 4:215-42. Oxford: Oxford University Press.

—. 2013. "Weighing Reasons.” Journal of Moral Philosophy 10: 70-86.

—. 2015. "Weighing Explanation." In Weighing and Reasoning: Themes from the Work of John Broome, edited by Iwao Hirose and Andrew Reisner, 232-51. New York: Oxford University Press.

Lee, Kok Yong. 2020. “On How to Take Normative Reasons to Be Evidence about Oughts." Soochow Journal of Philosophical Studies 41: 1-33.

Littlejohn, Clayton. 2011. "Evidence and Knowledge.” Erkenntnis 74: 241-62.

— 2016. "Do Reasons and Evidence Share the Same Residence?" Philosophy and Phenomenological Research 93 (3): 720-27. 
McKeever, Sean, and Michael Ridge. 2012. “Elusive Reasons.” In Oxford Studies in Metaethics, edited by Russ Shafer-Landau, 7:110-37. New York: Oxford University Press.

Metz, Euan K. H. 2018. "Reasons and Oughts: An Explanation and Defence of Deontic Buck-Passing." Ph.D. Thesis, The University of Reading, Berkshire.

Nagel, Thomas. 1979. The Possibility of Altruism. Princeton: Princeton University Press.

Nebel, Jacob M. 2018. "Normative Reasons as Reasons Why We Ought.” Mind 128(510): 459- 484.

Parfit, Derek. 2011. On What Matters. Vol. 1. Oxford: Oxford University Press.

Scanlon, Thomas M. 1998. What We Owe to Each Other. Cambridge, Mass.: The Belknap Press of Harvard University Press.

Snedegar, Justin. 2018. "Reasons for and Reasons against.” Philosophical Studies: An International Journal for Philosophy in the Analytic Tradition 175(3): 725-743.

Thomson, Judith Jarvis. 2008. Normativity. Chicago and La Salle: Open Court.

Whiting, Daniel. 2018. "Reasons in Some Respects: Reasons as Evidence.” Philosophical Studies: An International Journal for Philosophy in the Analytic Tradition 175(9): 2191-2208.

Williams, Bernard. 1973. "Ethical Consistency." In Problems of the Self: Philosophical Papers 1956-1972, 166-86. Cambridge: Cambridge University Press.

Williamson, Timothy. 2000. Knowledge and Its Limits. Oxford: Clarendon Press. 